\title{
Chronic Pain and DepressionAmong Primary Care Patients Treated with Buprenorphine
}

\author{
Michael D. Stein, $M D^{1,2}$, Debra S. Herman, PhD ${ }^{1,2}$, Genie L. Bailey, MD ${ }^{2,3}$, John Straus, MD², \\ Bradley J. Anderson, $P h D^{7}$, Lisa A. Uebelacker, $P h D^{1,2}$, and Risa B. Weisberg, PhD ${ }^{2}$
}

'Butler Hospital, Providence, Rhode Island, Providence, RI, USA; ${ }^{2}$ Alpert Medical School of Brown University, Providence, RI, USA; ${ }^{3}$ Stanley Street Treatment and Resources, Fall River, MA, USA.

BACKGROUND: Pain and depression are each prevalent among opioid dependent patients receiving maintenance buprenorphine, but their interaction has not been studied in primary care patients.

OBJECTIVE: We set out to examine the relationship between chronic pain, depression, and ongoing substance use, among persons maintained on buprenorphine in primary care settings.

DESIGN: Between September 2012 and December 2013. we interviewed buprenorphine patients at three practice sites.

PARTICIPANTS: Opioid dependent persons at two private internal medicine offices and a federally qualified health center participated in the study.

MAIN MEASURES: Pain was measured in terms of chronicity, with chronic pain being defined as pain lasting at least 6 months; and in terms of severity, as measured by self-reported pain in the past week, measured on a 0-100 scale. We defined mild chronic pain as pain severity between 0 and 39 and lasting at least 6 months, and moderate/severe chronic pain as severity $\geq 40$ and lasting at least 6 months. To assess depression, we used the Center for Epidemiologic Studies Depression (CESD) ten-item symptom scale and the two-item Patient Health Questionnaire (PHQ-2).

KEY RESULTS: Among 328 participants, 169 reported no chronic pain, 56 reported mild chronic pain, and 103 reported moderate/severe chronic pain. Participants with moderate/severe chronic pain commonly used nonopioid pain medications (56.3\%) and antidepressants (44.7\%), yet also used marijuana, alcohol, or cocaine $(40.8 \%)$ to help relieve pain. Mean CESD scores were $7.1( \pm 6.8), 8.3( \pm 6.0)$, and $13.6( \pm 7.6)$ in the no chronic, mild, and moderate/severe pain groups, respectively. Controlling for covariates, higher CESD scores were associated with a higher likelihood of moderate/severe chronic pain relative to both no chronic pain $(\mathrm{OR}=1.09, p<0.001)$ and mild chronic pain (OR=1.06, $p=0.04$ ).

CONCLUSION: Many buprenorphine patients are receiving over-the-counter or prescribed pain medications, as well as antidepressants, and yet continue to have significant and disabling pain and depressive symptoms. There is a clear need to address the pain-depression nexus in novel ways.

Received August 22, 2014

Revised January 8, 2015

Accepted January 21, 2015

Published online February 13, 2015
KEY WORDS: buprenorphine; chronic pain; depression.

$\mathrm{J}$ Gen Intern Med 30(7):935-41

DOI: $10.1007 / \mathrm{s} 11606-015-3212-\mathrm{y}$

(c) Society of General Internal Medicine 2015

\section{BACKGROUND}

The most recent data from the 2012 National Survey on Drug Use and Health show that 2.5 million Americans met criteria for abuse or dependence of opioids, reflecting more than a $50 \%$ increase in the last decade. ${ }^{1}$ In the last year, approximately 1.5 million people have sought treatment for opioid dependence. ${ }^{1}$ Buprenorphine/naloxone (referred to here as buprenorphine), a long-acting partial opioid agonist, has emerged as a viable alternative to methadone with comparable outcomes and can be prescribed in primary care settings. ${ }^{2}$

Patients with a history of opioid use report high rates of experiencing pain $^{3-5}$ that is often severe and interferes with daily activities. ${ }^{3-8}$ Indeed, a large percentage of patients with opioid dependence who receive opioid agonist treatment report that pain preceded any use of addictive substances, ${ }^{3,6,9-11}$ and that the primary reason for starting opioid use was to reduce pain. ${ }^{9}$ Among buprenorphine patients, $36-48 \%$ report chronic pain. ${ }^{12-14}$ Thus, buprenorphine recipients report far higher rates of chronic pain than the $10 \%$ prevalence estimated in the general US population by the World Health Organization. $^{15,16}$

Heterogeneous clinical conditions account for the sites of pain - low back, legs, total body - that comprise the majority of pain complaints among opioid-dependent patients. ${ }^{6,17}$ Pain in this population has been attributed to past traumatic injuries, chronic medical conditions, human immunodeficiency virus and hepatitis $\mathrm{C}$ virus infection, ${ }^{18,19}$ opioid-induced hyperalgesia ${ }^{20}$ and non-specific factors unrelated to opioid withdrawal. ${ }^{17}$ While buprenorphine has analgesic properties, it is not typically initiated, dosed, or directed toward pain relief in opioid-dependent persons. ${ }^{21-24}$

Persistent pain is associated with negative substance use outcomes in persons receiving buprenorphine for opioid detoxification ${ }^{25}$ or as maintenance treatment. ${ }^{12}$ Unrelieved chronic pain contributes to early buprenorphine treatment termination. ${ }^{26}$ Pain also complicates ongoing opioid 
dependence treatment as sufferers often misuse other substances such as marijuana, alcohol, and cocaine to seek relief. $^{10,27}$

Depression is another common comorbidity among opioid dependent persons. Approximately one-third to one-half of buprenorphine and methadone recipients suffer from clinically meaningful depressive symptoms that may or may not meet Diagnostic and Statistical Manual of Mental Disorders (DSM) criteria for major depressive disorder. ${ }^{28-33}$ Amongst methadone patients, higher psychiatric distress is associated with lower general functioning. ${ }^{3,6,7}$ Several studies have reported that methadone-maintained persons with chronic pain have greater depressive symptoms ${ }^{3,8}$ and a greater probability of occupational disability compared to patients with no chronic pain. ${ }^{34}$ Importantly, as with chronic pain, depressive symptoms have been associated with greater likelihood of relapse in opioid dependent treatment patients. ${ }^{35}$

Fordyce et al. ${ }^{36}$ proposed an operant conditioning model of chronic pain in which, following an injury, avoidance behavior is negatively reinforced through the reduction of physical pain. This model postulates that avoidance of physical activity leads directly to a withdrawal of positive reinforcers (e.g., employment) and thereby increases depressive symptoms as well. ${ }^{37}$ Depression is a common consequence of having chronic pain, ${ }^{38}$ and pain symptoms predict the onset of depression. ${ }^{39,40}$ Although there may also be biological links, there are psychological connections between chronic pain and depression, both treated by primary care providers, which may be prominent in the treatment of buprenorphine patients.

\section{OBJECTIVE}

The goal of this study was to examine the relationship between chronic pain, substance use, and depression and its treatment among persons maintained on buprenorphine in primary care settings. We were particularly interested in the relationship between chronic pain and depression, which has not been studied in primary care patients with opioid dependence. We divided our sample into three clinically relevant groups - those with no chronic pain, those with mild chronic pain, and those with moderate-severe chronic pain - as more severe chronic pain has a greater impact on quality of life in general population samples. ${ }^{41-43}$ We hypothesized that there would be an association between more severe chronic pain and: 1) depression and increased use of antidepressant medication and counseling; 2) increased use of non-opioid pain medications; and 3) use of a substance (marijuana, alcohol or cocaine) to manage pain.

\section{DESIGN}

Participants. Between September 2012 and December 2013, we approached consecutive patients who had received buprenorphine treatment for at least 1 month at three primary care sites in southeastern New England. We recruited from two private internal medicine offices, one with a physician and nurse practitioner who provide primary care (site $1 ; n=72$ ), one with a physician working alone (site $2 ; n=48$ ); and one federally qualified community health center staffed by three internal medicine physicians with nursing support (site $3 ; n=208$ ).

Procedures. Procedures were identical across sites and approved by the Butler Hospital Institutional Review Board. On days when the research staff was assigned to the primary care site, staff approached consecutive patients and asked that they complete a brief interview as part of screening for a clinical trial addressing pain. All participants approached at site 1 verbally consented; at site 2 , six persons refused, and at site 3 , five patients did not complete the questionnaire because they did not speak English, and two refused.

Main Measures. Assessments were identical across the three sites. We assessed demographic characteristics, the duration of current buprenorphine treatment, and the current dose of buprenorphine.

To define chronic pain, we combined a question about current pain severity with a question about whether participants had pain persisting for at least the past 6 months. ${ }^{44,45}$ To assess pain severity, we asked participants to rate their average overall pain in the past week on a $0-100$ scale, with 0 being no pain and 100 being pain "as bad as you can imagine." 44 We defined three groups: no chronic pain (some of whom had acute pain lasting less than 6 months), mild chronic pain (i.e., pain severity between 0 and 39 in the past week, and pain for at least 6 months) moderate/severe chronic pain (i.e., pain severity was $\geq 40$ in the past week and pain for at least 6 months). We chose this cutoff based on its use as a threshold for inclusion in clinical trials of analgesics. ${ }^{46}$ We asked participants to self-report on the primary bodily location of pain. We used the Brief Pain Inventory interference scale (BPI-I) ${ }^{47}$ to assess the degree to which pain interfered with important aspects of life, including general activity, mood, walking ability, normal work (including home and housework), relations with others, sleep, and enjoyment of life; internal consistency reliability was 0.95 . Individuals who reported no pain in the past week were assigned a 0 on the BPI-I. Total BPI-I scores, averaged across the seven domains, ranged from 0 to 10. Participants also provided information on recent pain treatment: last month use of "prescription pain medication or over-the-counter pain medication," opioids ("not prescribed to you"), and "marijuana, alcohol or cocaine to manage pain." Participants also reported if they had a "chronic medical condition" (yes/no).

To assess depression, we used the Center for Epidemiologic Studies Depression scale (CESD), ten-item version. ${ }^{48}$ Internal consistency reliability for the CESD was 0.88 in this sample. We also assessed whether participants screened positive for 
depression using a standard cutoff of the two-item Patient Health Questionnaire $^{49}$ (PHQ-2; $\geq 3$ is a positive screen). We also assessed whether participants were currently receiving mental health counseling, and their current use of antidepressant medication.

Analytical Methods. We present descriptive statistics to summarize the characteristics of the sample. ANOVA and the Pearson $\chi^{2}$ test of independence were used to compare the three pain groups. Holm's ${ }^{50}$ step-down method was used to control the family-wise error rate when contrasting specific, different-sized groups. Specifically, comparisons involving the mild chronic pain ( $n=56)$ group were often not statistically significant, even though this group may be substantively similar to either the no chronic pain group or the moderate/severe chronic pain group.

We used multinomial logit models to estimate the adjusted associations between substance use (assessed with the single item: "marijuana, alcohol or cocaine to manage pain"), depression and depression treatment variables, and pain severity, and present adjusted odds-ratios controlling for covariates. The statistical significance of the overall association was tested using a likelihood ratio difference in chi-square tests comparing models with and without depression. Separate analyses were conducted to evaluate CESD and PHQ-2 measures of depression.

\section{KEY RESULTS}

Participants averaged $38.7( \pm 10.7)$ years of age, $142(43.3 \%)$ were female, and 297 (90.6\%) were non-Latino White. On average, participants had been receiving buprenorphine treatment for $34.3( \pm 27.6)$ months. Ninety-eight $(29.9 \%)$ reported no pain in the last week, $71(21.6 \%)$ reported acute but not chronic pain, $56(17.1 \%)$ reported mild chronic pain, and 103 $(31.4 \%)$ reported moderate or severe chronic pain. Of the 109 participants reporting non-opioid pain medication use, 87 (79.9\%) were using nonsteroidal anti-inflammatory drugs, $11(10 \%)$ were using gabapentin, 11 (10\%) were using acetaminophen, and eight (7.3\%) were using muscle relaxants. Mean daily doses of buprenorphine were $14.86 \mathrm{mg}(S D=$ 5.96), $16.95 \mathrm{mg}(S D=6.12)$, and $17.84 \mathrm{mg}(S D=5.51)$ in the no chronic pain, mild chronic pain, and moderate/severe chronic pain groups $(p=0.01)$. There were no significant differences in proportion of persons with no pain, mild pain and moderate/severe pain across the three primary care recruitment sites $(p=0.60)$.

The back was the most frequently cited pain location among participants with acute but not chronic pain $(36.5 \%)$, and among those with mild chronic pain (36.5\%) (Table 1). Over half $(51.5 \%)$ of persons with moderate/severe chronic pain reported they had pain in multiple locations, 24 (23.3\%) reported back pain, and $18(17.5 \%)$ cited joint pain.
Table 1. Primary Pain Locations in the Past Week

\begin{tabular}{|c|c|c|c|}
\hline Location & $\begin{array}{l}\text { Participants } \\
\text { with acute but } \\
\text { not chronic } \\
\text { pain }(n=71)\end{array}$ & $\begin{array}{l}\text { Participants } \\
\text { with mild } \\
\text { chronic pain } \\
\left(n=51^{*}\right)\end{array}$ & $\begin{array}{l}\text { Participants } \\
\text { with moderate/ } \\
\text { severe chronic } \\
\text { pain }(n=103)\end{array}$ \\
\hline Back & $27(36.5 \%)$ & $19(36.5 \%)$ & $24(23.3 \%)$ \\
\hline Neck & $0(0.0 \%)$ & $2(3.9 \%)$ & $0(0.0 \%)$ \\
\hline $\begin{array}{l}\text { Headache/ } \\
\text { migraine }\end{array}$ & $6(8.1 \%)$ & $1(1.9 \%)$ & $1(1.0 \%)$ \\
\hline $\begin{array}{l}\text { Stomach/ } \\
\text { abdomen }\end{array}$ & $6(8.1 \%)$ & $2(3.9 \%)$ & $5(4.9 \%)$ \\
\hline Joint pain & $17(23.0 \%)$ & $12(23.1 \%)$ & $18(17.5 \%)$ \\
\hline Neuropathy & $1(1.4 \%)$ & $1(1.9 \%)$ & $2(1.9 \%)$ \\
\hline $\begin{array}{l}\text { Multiple } \\
\text { locations }\end{array}$ & $14(18.9 \%)$ & $14(26.9 \%)$ & $53(51.5 \%)$ \\
\hline
\end{tabular}

*Five participants with missing locations

${ }^{t}$ The overall test of group difference was $\left(\chi^{2}=37.88, d f=16, p=0.002\right)$

Participants with moderate/severe chronic pain were significantly older and less likely to be non-Latino White than those with no chronic pain (Table 2). Employment status differed significantly across groups; those with moderate/severe chronic pain were also considerably more likely (47.6 \%) to receive Social Security Disability Insurance than those with no chronic pain $(18.9 \%)$ or those with mild chronic pain $(19.6 \%)$.

Compared to the other two groups, participants with moderate/severe chronic pain had substantively and significantly $(p<0.05)$ higher mean CESD depression scores and were significantly $(p<0.05)$ more likely to screen positive for depression on the PHQ-2. Mean CESD scores were 7.1 $( \pm 6.8), 8.3( \pm 6.0)$, and $13.6( \pm 7.6)$ in the no chronic, mild chronic, and moderate/severe chronic pain groups, respectively. The corresponding rates of screening positive for depression on the PHQ-2 were 12.4, 12.5 and $35.9 \%$.

Those with moderate/severe chronic pain reported the highest mean pain interference scores, $5.5( \pm 2.2)$. Mean pain interference scores were $1.9( \pm 1.7)$ in the mild chronic pain group and $1.1( \pm 2.2)$ in the no chronic pain group. Participants with no chronic pain $(23.7 \%)$ were significantly $(p<0.05)$ less likely to report a chronic medical condition than those with mild (48.2\%) or moderate/severe chronic pain (64.1\%). A similar pattern was observed with non-opioid pain medication use with rates of $15.4,44.6$, and $64.1 \%$ in the no chronic, mild, and moderate/severe chronic pain groups, respectively. Participants with moderate/severe chronic pain (40.8\%) were also significantly $(p<0.05)$ more likely to report using "marijuana, alcohol, or cocaine" for pain than those with either mild chronic $(16.1 \%)$ or no chronic pain $(7.7 \%)$.

Statistically significant between group differences were also observed with respect to current mental health counseling, and current antidepressant medication use (Table 2). Relative to those with no chronic or mild chronic pain, those with moderate/severe chronic pain had significantly $(p<0.05)$ higher rates of current mental health counseling. Those with moderate/severe chronic pain $(44.7 \%)$ were also significantly $(p<0.05)$ more likely to report they were currently taking an antidepressant than those with mild chronic pain $(21.4 \%)$. 
Table 2 Differences Between Participants with No Chronic Pain, Mild Chronic Pain, and Moderate/Severe Chronic Pain

\begin{tabular}{|c|c|c|c|c|}
\hline & \multicolumn{3}{|l|}{ Chronic pain } & \multirow[t]{3}{*}{ F or $\chi^{2 *}(\mathrm{p}=)$} \\
\hline & No $(n=169)$ & Mild $(n=56)$ & Moderate/Severe $(n=103)$ & \\
\hline & Mean ( \pm SD) or n (\%) & Mean $( \pm$ SD) or $n(\%)$ & Mean $( \pm$ SD) or $n(\%)$ & \\
\hline \multicolumn{5}{|l|}{ Site } \\
\hline 1 & $24(14.2 \%)$ & $11(19.6 \%)$ & $13(12.6 \%)$ & $4.46(0.347)$ \\
\hline 2 & $33(19.5 \%)$ & $10(17.9 \%)$ & $29(28.2 \%)$ & \\
\hline 3 & $112(66.3 \%)$ & $35(62.5 \%)$ & $61(59.2 \%)$ & \\
\hline Age & $36.9( \pm 10.8)$ & $39.0( \pm 10.1)$ & $41.6( \pm 10.5)^{t}$ & $6.44(0.002)$ \\
\hline Gender (Female) & $73(43.2 \%)$ & $23(41.1 \%)$ & $46(44.7 \%)$ & $0.19(0.909)$ \\
\hline Non-Latino White & $161(95.3 \%)$ & $49(87.5 \%)$ & $87(84.5 \%)$ & $9.46(0.009)$ \\
\hline Education & $12.6( \pm 2.1)$ & $12.2( \pm 1.6)$ & $12.0( \pm 2.3)^{4}$ & $3.14(0.045)$ \\
\hline \multicolumn{5}{|l|}{ Employment status } \\
\hline Full-Time & $88(52.1 \%)$ & $24(42.9 \%)$ & $27(26.2 \%)$ & $34.15(0.000)$ \\
\hline Part-Time & $14(8.3 \%)$ & $4(7.1 \%)$ & $10(9.7 \%)$ & \\
\hline Unemployed & $35(20.7 \%)$ & $17(30.4 \%)$ & $17(16.5 \%)$ & \\
\hline Disabled (SSDI) & $32(18.9 \%)$ & $11(19.6 \%)$ & $49(47.6 \%)$ & \\
\hline Chronic medical condition & $40(23.7 \%)$ & $27(48.2 \%)^{\dagger}$ & $66(64.1 \%)$ & $44.99(<0.001)$ \\
\hline CESD & $7.1( \pm 6.8)$ & $8.3( \pm 6.0)$ & $13.6( \pm 7.6)^{48}$ & $28.75(<0.001)$ \\
\hline PHQ-2 $\geq 3$ & $21(12.4 \%)$ & $7(12.5 \%)$ & $37(35.9 \%)^{\S}$ & $24.5(<0.001)$ \\
\hline Brief pain interference index & $1.1( \pm 2.2)$ & $1.9( \pm 1.7)^{\dagger}$ & $5.5( \pm 2.2)^{ \pm \S}$ & $138.7(<0.001)$ \\
\hline Used MJ, Alc., or cocaine for pain" & $13(7.7 \%)$ & $9(16.1 \%)$ & $42(40.8 \%)^{\ddagger \S}$ & $45.11(<0.001)$ \\
\hline Non-prescribed opiate use & $11(6.5 \%)$ & $2(3.6 \%)$ & $11(10.7 \%)$ & $3.04(0.219)$ \\
\hline Current non-opioid pain med use & $26(15.4 \%)$ & $25(44.6 \%)^{\dagger}$ & $58(56.3 \%)^{*}$ & $52.27(<0.001)$ \\
\hline Prescribed opioids for pain & $4(2.4 \%)$ & $0(0.0 \%)$ & $1(1.0 \%)$ & $(0.062)^{9}$ \\
\hline Current mental health counseling & $39(23.1 \%)$ & $8(14.3 \%)$ & $38(36.9 \%)^{\ddagger \S}$ & $11.12(0.004)$ \\
\hline Currently taking antidepressant & $54(32.0 \%)$ & $12(21.4 \%)$ & $46(44.7 \%)^{\S}$ & $9.45(0.009)$ \\
\hline
\end{tabular}

*Degrees of Freedom is 2 for all $\chi^{2}$ tests except site $(d f=4)$ and employment status $(d f=8)$. Degrees of freedom for all F-tests are 2 and 325

${ }^{\dagger}$ Mild chronic pain group significantly $(p<0.05)$ different than no chronic pain group

${ }^{*}$ Moderate/severe chronic pain group significantly $(p<0.05)$ different than no chronic pain group

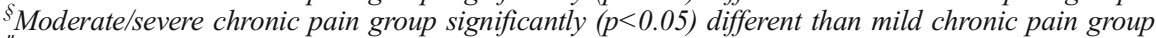

"Any use in the past month (Yes)

"Fisher's exact $p$ value

We estimated a multinomial logit model to evaluate the adjusted association between pain category and depression (Table 3). Covariates included all of the variables described in Table 2 except the brief pain interference index (highly correlated with chronic pain) and receipt of prescription opioids for pain (only five persons). Separate models were evaluated for CESD and PHQ-2. An examination of variance inflation (VIF) statistics for the covariance matrix did not suggest that multicollinearity threatened to confound interpretation; the mean VIF was 1.38. After adjusting for covariates, the association between CESD and pain severity was statistically significant (LR $2=14.56, p<0.001$ ). Higher CESD scores were associated with a higher likelihood of moderate/severe chronic pain relative to both no chronic pain $(O R=1.09$, $p<0.001)$ and mild chronic pain $(O R=1.06, p=0.04)$. CESD scores did not significantly distinguish persons with mild chronic pain from persons with no chronic pain $(O R=1.03$, $p=0.31)$. The PHQ-2 was also associated significantly (LR2 $=6.52, p=0.04$ ) with pain severity after adjusting for covariates. Relative to participants with no chronic pain, persons screening positive on the PHQ-2 had a significantly higher likelihood of having moderate/severe chronic pain $(O R=2.30, p=0.05)$; the coefficient contrasting the odds of moderate/severe chronic pain versus mild chronic pain was similar $(O R=2.53, p=0.07)$. The PHQ-2 did not distinguish persons with mild chronic pain from persons with no chronic pain $(O R=0.91, p=0.86)$.

\section{CONCLUSIONS}

Chronic pain is common among primary care patients receiving buprenorphine and is frequently moderate to severe in nature. The overall rate of chronic pain in the study ( $48 \%$ ) is similar to that reported in substance abuse treatment settings that provide buprenorphine or methadone. We found that many patients are receiving additional over-the-counter or prescribed pain medications, as well as antidepressants, and yet they continue to have significant and disabling pain and depressive symptoms. Further, we found that patients with moderate/severe chronic pain were also more likely to be using substances such as marijuana, alcohol, and cocaine to manage their pain. Our study highlights the importance of primary care providers routinely evaluating chronic pain and mood during buprenorphine treatment in order to assist patients in coping with these two inter-related conditions.

The comorbidity of chronic pain and depression is of special concern for many reasons. First, when compared to individuals with major depression but without chronic pain, those with chronic pain have depressive symptoms of longer duration ${ }^{51}$ and greater severity. ${ }^{52}$ Second, in comparison to those without chronic pain, individuals with chronic pain have twice the risk for suicide. ${ }^{53}$ Among depressed inpatients ${ }^{54}$ and outpatients, ${ }^{51}$ chronic pain increases the risk of suicidal ideation. Third, comorbid chronic pain and depression is associated with more disability than either condition alone. ${ }^{55}$ Fourth, the combination of chronic pain and depression may increase health care costs in a multiplicative fashion. ${ }^{56}$ 
Table 3. Multinomial Logit Model Regression Chronic Pain Category on Demographic Characteristics, Medical Condition, Pain Medication Use, Other Substance Use, and CESD $(n=328)$

\begin{tabular}{|c|c|c|c|c|}
\hline & \multicolumn{3}{|l|}{ Contrast $^{*}$} & \multirow[t]{2}{*}{$\mathbf{L R}^{2}(\mathbf{p}=)^{\|}$} \\
\hline & $\begin{array}{l}\text { Mild/None }{ }^{\dagger} \text { OR } \\
\text { (95\% CI) }\end{array}$ & $\begin{array}{l}\text { Mod+/None }{ }^{*} \text { OR } \\
(95 \% \text { CI })\end{array}$ & $\begin{array}{l}\text { Mod+/Mild }{ }^{\S} \text { OR } \\
(95 \% \text { CI })\end{array}$ & \\
\hline \multicolumn{5}{|l|}{ Site } \\
\hline 2 & $1.01(0.30 ; 3.43)$ & $1.89(0.60 ; 5.97)$ & $1.87(0.52 ; 6.69)$ & $1.63(0.803)$ \\
\hline 3 & $1.08(0.39 ; 2.98)$ & $1.29(0.47 ; 3.52)$ & $1.19(0.39 ; 3.60)$ & \\
\hline 1 & {$[1.00]$} & {$[1.00]$} & {$[1.00]$} & \\
\hline Age & $1.01(0.98 ; 1.05)$ & $1.01(0.97 ; 1.05)$ & $0.99(0.96 ; 1.04)$ & $0.50(0.779)$ \\
\hline Gender (Female) & $1.23(0.57 ; 2.62)$ & $1.22(0.60 ; 2.47)$ & $0.99(0.44 ; 2.26)$ & $0.43(0.808)$ \\
\hline Non-Latino White & $0.31(0.09 ; 1.04)$ & $0.32(0.10 ; 1.06)$ & $1.04(0.33 ; 3.26)$ & $4.81(0.090)$ \\
\hline Education & $0.94(0.78 ; 1.14)$ & $0.96(0.81 ; 1.13)$ & $1.01(0.84 ; 1.23)$ & $0.44(0.803)$ \\
\hline \multicolumn{5}{|l|}{ Employment status } \\
\hline Part-Time & $0.98(0.24 ; 3.95)$ & $1.75(0.5315 .81)$ & $1.79(0.42 ; 7.67)$ & $8.55(0.201)$ \\
\hline Unemployed & $2.16(0.86 ; 5.37)$ & $1.68(0.63 ; 4.48)$ & $0.78(0.27 ; 2.27)$ & \\
\hline Disabled (SSDI) & $0.94(0.31 ; 2.83)$ & $2.47(0.94 ; 6.51)$ & $2.63(0.85 ; 8.16))$ & \\
\hline Full-Time [REF] & [1.00] & {$[1.00]$} & {$[1.00]$} & \\
\hline Chronic Med. Condition & $3.13(1.46 ; 6.67))^{4}$ & $3.73(1.86 ; 7.50)^{6}$ & $1.19(0.53 ; 2.67)$ & $16.93(<0.001)$ \\
\hline Used MJ, Alc., or cocaine for pain & $1.90(0.67 ; 5.36)$ & $6.43(2.77 ; 14.95)^{\top}$ & $3.39(1.35 ; 8.53)^{\natural}$ & $21.96(<0.001)$ \\
\hline Non-prescribed opiate use & $0.47(0.09 ; 2.55)$ & $0.73(0.21 ; 2.52)$ & $1.55(0.29 ; 8.23)$ & $0.87(0.647)$ \\
\hline Current non-opioid pain med use & $5.29(2.47 ; 11.31))^{\pi}$ & $5.50(20.73 ; 11.07))^{\llbracket}$ & $1.04(0.49 ; 2.21)$ & $30.94(<0.001)$ \\
\hline Current mental health counseling & $0.36(0.13 ; 0.99)^{\# \prime}$ & $0.47(0.21 ; 1.07)$ & $1.33(0.48 ; 3.66)$ & $5.35(0.069)$ \\
\hline Currently taking antidepressant & $0.57(0.24 ; 1.33)$ & $1.06(0.51 ; 2.22)$ & $1.87(0.76 ; 4.58)$ & $2.26(0.324)$ \\
\hline CESD & $1.03(0.97 ; 1.09)$ & $1.09(1.04 ; 1.14)^{\top}$ & $1.06(1.00 ; 1.12)^{\#}$ & $13.05(0.002)$ \\
\hline
\end{tabular}

*In a multinomial logit model with a three-category outcome, only two of the three possible coefficients contrasting the outcome categories are independent. We present all three coefficients to more fully describe the results

${ }^{\prime}$ Estimated odds of mild chronic pain versus no chronic pain

${ }^{7}$ Estimated odds of moderate/severe chronic pain versus no chronic pain

${ }^{\S}$ Estimated odds of moderate/severe chronic pain versus mild chronic pain

"Difference in likelihood-ratio chi-square test. This statistic has $2^{\circ}$ of freedom except for employment status, which has $6^{\circ}$ of freedom

${ }^{\mathrm{T}} p<0.01$
${ }^{\#} p<0.05$

In the present study, depression symptom severity and screening positive for depression was highest in those with moderate/ severe chronic pain, followed by those with mild chronic pain. The relationship between depression and chronic pain is well documented in other chronic conditions, and is likely bidirectional. $^{38,57}$. Banks and Kerns suggest that having a chronic medical condition increases depression risk, and that the specific nature of chronic pain increases this risk further, noting that pain is "inextricably associated with negative affect." 38 Pain is aversive and seemingly psychologically inescapable; it follows that a substantial minority of patients with chronic pain experience depression. Conversely, being depressed predicts the development of chronic pain (e.g., the conversion of acute low back pain to chronic low back pain), ${ }^{58}$ likely through varied mechanisms, including decreased engagement in physical activity ${ }^{59}$ or increased attention to somatic symptoms.

The depression-pain nexus was addressed by clinicians at these primary care sites, as evidenced by the prescription of antidepressant medication with the moderate-severe pain group having the highest rate $(45 \%)$. Of note, there was no significant difference in antidepressant use between the moderate/severe pain and no chronic pain groups. This suggests that those without chronic pain may have coped better with their depression compared to persons with moderate/ severe pain (as corroborated by differences between groups in acquiring SSDI). This finding may also be in part explained by antidepressants having analgesic effects in some buprenorphine patients, ${ }^{14}$ treating fibromyalgia, some types of neuropathic pain, and headaches, ${ }^{60}$ although data does not suggest that antidepressants are in general beneficial for nonspecific low back pain or other musculoskeletal symptoms. ${ }^{60}$ Mental health counseling was received at nearly the same rate as antidepressant medication; however, no participant reported receiving counseling specifically for chronic pain. ${ }^{61}$

Chronic pain patients received modestly but significantly higher buprenorphine doses than patients without pain, similar to reports from methadone maintenance treatment (MMT) programs. $^{7}$ As one might expect, there was also a graded positive relationship between chronic pain and non-opioid pain medication use. However, compared to those without pain, buprenorphine patients with pain (again in a graded fashion based on severity of pain) reported higher misuse rates of additional substances that may produce analgesia, including cocaine, alcohol, and marijuana. ${ }^{10,12,27}$ Patients may view this ongoing use of non-prescribed, psychoactive drugs during buprenorphine treatment as self-medication of pain and/or psychiatric symptoms, or as an attempt to improve subjective well-being. ${ }^{6,7,11,13,34}$ Nonetheless, ongoing use of other nonprescribed substances may lead to discharge from buprenorphine treatment.

Even though overall rates of unemployment were high in this sample, chronic pain was associated with a 
higher likelihood of receiving disability payments. This is to be expected, given that moderate/severe chronic pain may be judged to interfere with one's ability to work. ${ }^{14}$ Self-report of having a chronic illness was associated with increased likelihood of reporting chronic pain. While illnesses were not specified, these may be surrogates for general debility, or for other chronic diseases associated with pain (e.g., diabetes, osteoarthritis). Interestingly though, there was no significant difference between the group with mild chronic pain and those with moderate / severe chronic pain with regard to reported chronic medical conditions. Thus, in this sample, having a chronic medical condition may have accounted for the presence, but not the severity, of patients' chronic pain.

There are several limitations of this study. First, it is cross-sectional in nature, and therefore it is impossible to disentangle cause and effect between pain and depression. Second, although we looked at particular symptoms (e.g., depression symptoms), we did not determine whether participants met formal diagnostic criteria for DSM disorders, such as major depression or substance abuse/ dependence. Third, we assessed substance misuse with a single question that combined marijuana, alcohol and cocaine, substances, which could be separated in future studies, where we might also assess benzodiazepine use. Fourth, we did not assess whether buprenorphine, which has a short analgesic effect and is not approved for treatment of chronic pain, was used in divided daily doses. Nor did we assess use of alternative medicine treatments for pain relief. ${ }^{27,62}$

Although buprenorphine maintenance treatment has many health benefits, and buprenorphine has analgesic properties, full relief from chronic pain should not be expected. Still, the physical and psychological distress of patients with pain influences the perception of treatment benefits by both patients and providers. Patient pain is associated with lesser satisfaction with treatment, provider frustration, ${ }^{63}$ and may interfere with visit attendance, while also hindering the search for employment. ${ }^{64-66}$

The substantial overlap of pain and depression in buprenorphine patients suggests that functioning may improve most when depression and pain are simultaneously treated in an integrated fashion. Primary care providers' attention to and referral for non-medication treatments such as cognitivebehavioral or mindfulness-based psychotherapy specifically targeted towards chronic pain, as well as recommendations for trials of other alternative methods of analgesia (acupuncture, yoga) may reduce disability, depression, and the escalating non-opioid substance abuse in this population.

Acknowledgements: Contributors: We'd like to thank Allison Borges for her data collection work on this project.

Funders: This study was supported by NIDA grant R34DA032800. Dr. Stein is a recipient of NIDA Award K24 DA000512.
Prior Presentations: None.

Conflict of Interest: Dr. Bailey's institution has received grant support from Titan Pharmaceuticals, Inc., BioDelivery Sciences International, Inc. and Orexo. She has received travel support from Titan Pharmaceuticals, Inc. and is on the advisory boards of Braeburn Pharmaceuticals, BioDelivery Sciences International, Inc. and Camurus AB. All other authors declare that they do not have a conflict of interest.

Corresponding Author: Michael D. Stein, M.D.; Butler Hospital, Providence, Rhode Island, 345 Blackstone Boulevard, Providence, RI 02906, USA (e-mail: Michael_Stein@Brown.edu).

\section{REFERENCES}

1. Substance Abuse and Mental Health Services Administration. Results from the 2012 National Survey on Drug Use and Health: Summary of National Findings, NSDUH Series H-46, HHS Publication No. (SMA) 13-4795 ed. Rockville, MD: Substance Abuse and Mental Health Services Administration; 2013.

2. Mattick RP, Breen C, Kimber J, Davoli M. Buprenorphine maintenance versus placebo or methadone maintenance for opioid dependence. Cochrane Database Syst Rev. 2014;2:CD002207.

3. Rosenblum A, Joseph H, Fong C, Kipnis S, Cleland C, Portenoy RK. Prevalence and characteristics of chronic pain among chemically dependent patients in methadone maintenance and residential treatment facilities. JAMA. 2003;289(18):2370-8.

4. Sheu R, Lussier D, Rosenblum A, et al. Prevalence and characteristics of chronic pain in patients admitted to an outpatient drug and alcohol treatment program. Pain Med. 2008;9(7):911-7.

5. Karasz A, Zallman L, Berg K, Gourevitch M, Selwyn P, Arnsten JH. The experience of chronic severe pain in patients undergoing methadone maintenance treatment. J Pain Symptom Manage. 2004;28(5):517-25.

6. Jamison RN, Kauffman J, Katz NP. Characteristics of methadone maintenance patients with chronic pain. J Pain Symptom Manage. 2000; 19(1):53-62.

7. Peles E, Schreiber S, Gordon J, Adelson M. Significantly higher methadone dose for methadone maintenance treatment (MMT) patients with chronic pain. Pain. 2005;113(3):340-6.

8. Barry DT, Beitel M, Garnet B, Joshi D, Rosenblum A, Schottenfeld RS. Relations among psychopathology, substance use, and physical pain experiences in methadone-maintained patients. J Clin Psychiatry. 2009;70(9): 1213-1218. PMCID: PMC2760669.

9. Brands B, Blake J, Sproule B, Gourlay D, Busto U. Prescription opioid abuse in patients presenting for methadone maintenance treatment. Drug Alcohol Depend. 2004;73(2):199-207.

10. Trafton JA, Oliva EM, Horst DA, Minkel JD, Humphreys K. Treatment needs associated with pain in substance use disorder patients: implications for concurrent treatment. Drug Alcohol Depend. 2004;73(1):23-31.

11. Rosenblum A, Parrino M, Schnoll SH, et al. Prescription opioid abuse among enrollees into methadone maintenance treatment. Drug Alcohol Depend. 2007;90(1):64-71.

12. Barry DT, Savant JD, Beitel M, et al. Pain and associated substance use among opioid dependent individuals seeking office-based treatment with buprenorphine-naloxone: a needs assessment study. Am J Addict. 2013;22(3):212-217. PMCID: PMC3641684.

13. Mark TL, Dilonardo J, Vandivort R, Miller K. Psychiatric and medical comorbidities, associated pain, and health care utilization of patients prescribed buprenorphine. J Subst Abuse Treat. 2013;44(5):481-7.

14. Tsui JI, Herman DS, Kettavong M, Anderson BJ, Stein MD. Escitalopram is associated with reductions in pain severity and pain interference in opioid dependent patients with depressive symptoms. Pain. 2011;152(11):2640-2644. PMCID: PMC3235744.

15. Gureje O, Von Korff M, Simon GE, Gater R. Persistent pain and wellbeing: a World Health Organization Study in Primary Care. JAMA. 1998;280(2): 147-51.

16. Portenoy RK, Ugarte C, Fuller I, Haas G. Population-based survey of pain in the United States: differences among white, African American, and Hispanic subjects. J Pain. 2004;5(6):317-28.

17. Barry DT, Beitel M, Joshi D, Schottenfeld RS. Pain and substancerelated pain-reduction behaviors among opioid dependent individuals seeking methadone maintenance treatment. Am J Addict. 2009;18(2):117-21. PMCID: PMC2679697. 
18. Silberbogen AK, Janke EA, Hebenstreit C. A closer look at pain and hepatitis C: preliminary data from a veteran population. J Rehabil Res Dev. 2007;44(2):231-44.

19. Thompson ME, Barkhuizen A. Fibromyalgia, hepatitis $\mathrm{C}$ infection, and the cytokine connection. Curr Pain Headache Rep. 2003;7(5):342-7.

20. Chu LF, Angst MS, Clark D. Opioid-induced hyperalgesia in humans: molecular mechanisms and clinical considerations. Clin J Pain. 2008;24(6):479-96.

21. Blondell RD, Ashrafioun L, Dambra CM, Foschio EM, Zielinski AL, Salcedo DM. A Clinical Trial Comparing Tapering Doses of Buprenorphine with Steady Doses for Chronic Pain and Co-existent Opioid Addiction. J Addict Med. 2010;4(3):140-6. PMCID: PMC2931595.

22. Jones JD, Sullivan MA, Manubay J, Vosburg SK, Comer SD. The subjective, reinforcing, and analgesic effects of oxycodone in patients with chronic, non-malignant pain who are maintained on sublingual buprenorphine/naloxone. Neuropsychopharmacology. 2011;36(2):411-22. PMCID: PMC3055661.

23. Malinoff HL, Barkin RL, Wilson G. Sublingual buprenorphine is effective in the treatment of chronic pain syndrome. Am J Ther. 2005;12(5):379-84.

24. Neumann AM, Blondell RD, Jaanimagi U, et al. A preliminary study comparing methadone and buprenorphine in patients with chronic pain and coexistent opioid addiction. Addict Dis. 2013;32(1):68-78. PMCID: PMC3604999.

25. Potter JS, Chakrabarti A, Domier CP, Hillhouse MP, Weiss RD, Ling W. Pain and continued opioid use in individuals receiving buprenorphinenaloxone for opioid detoxification: secondary analyses from the Clinical Trials Network. J Subst Abuse Treat. 2010;38(Suppl 1):S80-86. PMCID: PMC3150507.

26. Neumann AM, Blondell RD, Azadfard M, Nathan G, Homish GG. Primary care patient characteristics associated with completion of 6month buprenorphine treatment. Addict Behav. 2013;38(11):2724-8.

27. Barry DT, Beitel M, Cutter CJ, et al. Allopathic, complementary, and alternative medical treatment utilization for pain among methadonemaintained patients. Am J Addict. 2009;18(5):379-85. PMCID PMC2777756.

28. Brienza RS, Stein MD, Chen M, et al. Depression among needle exchange program and methadone maintenance clients. J Subst Abuse Treat. 2000; 18(4):331-7.

29. Rounsaville B, Weissman $\mathbf{M}$, Crits-Christoph $\mathbf{K}$, Wilber $\mathbf{C}$, Kleber $\mathbf{H}$. Diagnosis and symptoms of depression in opiate addicts: course and relationship to treatment outcome. Arch Gen Psychiatry. 1982;39(2):151-6.

30. Brooner R, King V, Kidorf M, Schmidt C Jr, Bigelow G. Psychiatric and substance use comorbidity among treatment-seeking opioid abusers. Arch Gen Psychiatry. 1997;54(1):71-80.

31. Kidorf M, Disney ER, King VL, Neufeld K, Beilenson PL, Brooner RK. Prevalence of psychiatric and substance use disorders in opioid abusers in a community syringe exchange program. Drug Alcohol Depend. 2004;74(2):115-22

32. Nunes EV, Sullivan MA, Levin FR. Treatment of depression in patients with opiate dependence. Biol Psychiatry. 2004;56(10):793-802.

33. Stein MD, Herman DS, Kettavong M, et al. Antidepressant treatment does not improve buprenorphine retention among opioid-dependent persons. J Subst Abuse Treat. 2010;39(2):157-66. PMCID: PMC2910850.

34. Potter JS, Prather K, Weiss RD. Physical pain and associated clinical characteristics in treatment-seeking patients in four substance use disorder treatment modalities. Am J Addict. 2008;17(2):121-5.

35. Larson MJ, Paasche-Orlow M, Cheng DM, Lloyd-Travaglini C, Saitz $\mathbf{R}$, Samet JH. Persistent pain is associated with substance use after detoxification: a prospective cohort analysis. Addiction. 2007;102(5):752-60.

36. Fordyce WE, Shelton JL, Dundore DE. The modification of avoidance learning pain behaviors. J Behav Med. 1982;5(4):405-14

37. Vlaeyen JW, Linton SJ. Fear-avoidance and its consequences in chronic musculoskeletal pain: a state of the art. Pain. 2000;85(3):317-32.

38. Banks SM, Kerns RD. Explaining high rates of depression in chronic pain: a diathesis-stress framework. Psychol Bull. 1996;119:95-110.

39. Nakao M, Yano E. Somatic symptoms for predicting depression: one-year follow-up study in annual health examinations. Psychiatry Clin Neurosci. 2006;60(2):219-25.

40. Barkow K, Heun R, Ustun TB, Maier W. Identification of items which predict later development of depression in primary health care. Eur Arch Psychiatry Clin Neurosci. 2001;251(Suppl 2):II21-26.

41. Grotle M, Foster NE, Dunn KM, Croft P. Are prognostic indicators for poor outcome different for acute and chronic low back pain consulters in primary care? Pain. 2010;151(3):790-7. PMCID: PMC3398128.
42. Langley PC. The societal burden of pain in Germany: health-related quality-of-life, health status and direct medical costs. J Med Econ. 2012;15(6):1201-15.

43. Gatchel RJ, Bernstein D, Stowell AW, Pransky G. Psychosocial differences between high-risk acute vs. chronic low back pain patients. Pain Pract. 2008;8(2):91-7.

44. Dworkin RH, Turk DC, Farrar JT, et al. Core outcome measures for chronic pain clinical trials: IMMPACT recommendations. Pain. 2005;113(12):9-19.

45. Landmark T, Romundstad P, Dale O, Borchgrevink PC, Kaasa S Estimating the prevalence of chronic pain: validation of recall against longitudinal reporting (the HUNT pain study). Pain. 2012;153(7):1368-73.

46. Dworkin RH, Turk DC, Peirce-Sandner S, et al. Considerations for improving assay sensitivity in chronic pain clinical trials: IMMPACT recommendations. Pain. 2012;153(6):1148-58.

47. Cleeland CS, Ryan KM. Pain assessment: global use of the Brief Pain Inventory. Ann Acad Med Singapore. 1994;23(2):129-38.

48. Andresen EM, Malmgren JA, Carter WB, Patrick DL. Screening for depression in well older adults: evaluation of a short form of the CES-D (Center for Epidemiologic Studies Depression Scale). Am J Prev Med. 1994;10(2):77-84.

49. Kroenke K, Spitzer RL, Williams JB. The Patient Health Questionnaire-2 validity of a two-item depression screener. Med Care. 2003;41(11):128492.

50. Holm S. A simple sequentially rejective multiple test procedure. Scand J Statist. 1979;6:65-70.

51. Karp JF, Scott J, Houck P, Reynolds CF 3rd, Kupfer DJ, Frank E. Pain predicts longer time to remission during treatment of recurrent depression. J Clin Psychiatry. 2005;66(5):591-7.

52. Ohayon MM. Specific characteristics of the pain/depression association in the general population. J Clin Psychiatry. 2004;65(Suppl 12):5-9.

53. Tang NK, Crane C. Suicidality in chronic pain: a review of the prevalence, risk factors and psychological links. Psychol Med. 2006;36(5):575-86.

54. Meeks TW, Dunn LB, Kim DS, et al. Chronic pain and depression among geriatric psychiatry inpatients. Int $\mathrm{J}$ Geriatr Psychiatry. 2008;23(6):63742.

55. Currie SR, Wang J. Chronic back pain and major depression in the general Canadian population. Pain. 2004;107(1-2):54-60.

56. Gameroff MJ, Olfson M. Major depressive disorder, somatic pain, and health care costs in an urban primary care practice. J Clin Psychiatry. 2006;67(8):1232-9.

57. Currie SR, Wang J. More data on major depression as an antecedent risk factor for first onset of chronic back pain. Psychol Med. 2005;35(9):127582.

58. Melloh M, Elfering A, Egli Presland C, et al. Predicting the transition from acute to persistent low back pain. Occup Med (Lond). 2011;61(2):12731 .

59. Harkapaa K, Jarvikoski A, Mellin G, Hurri H, Luoma J. Health locus of control beliefs and psychological distress as predictors for treatment outcome in low-back pain patients: results of a 3-month follow-up of a controlled intervention study. Pain. 1991;46(1):35-41.

60. Mercier A, Auger-Aubin I, Lebeau JP, et al. Evidence of prescription of antidepressants for non-psychiatric conditions in primary care: an analysis of guidelines and systematic reviews. BMC Fam Pract. 2013;14:55. PMCID: PMC3648410.

61. Kerns RD, Sellinger J, Goodin BR. Psychological treatment of chronic pain. Annu Rev Clin Psychol. 2011;7:411-34.

62. Barry DT, Savant JD, Beitel M, et al. Use of conventional, complementary, and alternative treatments for pain among individuals seeking primary care treatment with buprenorphine-naloxone. J Addict Med. 2012;6(4):274-9. PMCID: PMC3492534.

63. Barry DT, Bernard MJ, Beitel M, Moore BA, Kerns RD, Schottenfeld RS. Counselors' Experiences Treating Methadone-maintained Patients with Chronic Pain: A Needs Assessment Study. J Addict Med. 2008;2(2): 108-11

64. Ilgen MA, Trafton JA, Humphreys $\mathbf{K}$. Response to methadone maintenance treatment of opiate dependent patients with and without significant pain. Drug Alcohol Depend. 2006;82(3):187-93.

65. Currie SR, Hodgins DC, Crabtree A, Jacobi J, Armstrong S. Outcome from integrated pain management treatment for recovering substance abusers. J Pain. 2003;4(2):91-100.

66. Clark MR, Stoller KB, Brooner RK. Assessment and management of chronic pain in individuals seeking treatment for opioid dependence disorder. Can J Psychiatry. 2008;53(8):496-508. 